\title{
Temperature-Induced Lattice Relaxation of Perovskite Crystal Enhances Optoelectronic Properties and Solar Cell Performance
}

Banavoth Murali, Emre Yengel, Wei Peng, Zhijie Chen, Mohd S. Alias, Erkki Alarousu, Boon S. Ooi, Victor M. Burlakov, Alain Goriely, Mohamed Eddaoudi, Osman M. Bakr, and Omar F. Mohammed

J. Phys. Chem. Lett., Just Accepted Manuscript • DOI: 10.1021/acs.jpclett.6b02684 • Publication Date (Web): 14 Dec 2016

Downloaded from http://pubs.acs.org on December 14, 2016

\section{Just Accepted}

"Just Accepted" manuscripts have been peer-reviewed and accepted for publication. They are posted online prior to technical editing, formatting for publication and author proofing. The American Chemical Society provides "Just Accepted" as a free service to the research community to expedite the dissemination of scientific material as soon as possible after acceptance. "Just Accepted" manuscripts appear in full in PDF format accompanied by an HTML abstract. "Just Accepted" manuscripts have been fully peer reviewed, but should not be considered the official version of record. They are accessible to all readers and citable by the Digital Object Identifier (DOI®). "Just Accepted" is an optional service offered to authors. Therefore, the "Just Accepted" Web site may not include all articles that will be published in the journal. After a manuscript is technically edited and formatted, it will be removed from the "Just Accepted" Web site and published as an ASAP article. Note that technical editing may introduce minor changes to the manuscript text and/or graphics which could affect content, and all legal disclaimers and ethical guidelines that apply to the journal pertain. ACS cannot be held responsible for errors or consequences arising from the use of information contained in these "Just Accepted" manuscripts. 


\title{
Temperature-Induced Lattice Relaxation of
}

\section{Perovskite Crystal Enhances Optoelectronic}

\section{Properties and Solar Cell Performance}

\author{
Banavoth Murali ${ }^{\dagger}$, Emre Yengel ${ }^{\dagger}$, Wei Peng ${ }^{\dagger}$, Zhijie Chen $^{\star}$, Mohd S. Alias $^{\text {Il }}$,Erkki Alarousu ${ }^{\dagger}$ \\ Boon S. Ooi ${ }^{\text {II }}$,Victor Burlakov ${ }^{\S}$, Alain Goriely ${ }^{\S}$, Mohamed Eddaoudi ${ }^{\ddagger}$,Osman M. Bakr ${ }^{\dagger}$, and \\ Omar F. Mohammed ${ }^{\dagger} *$
}

${ }^{\dagger}$ King Abdullah University of Science and Technology, KAUST Solar Center, Division of Physical Sciences and Engineering, Thuwal 23955-6900, Kingdom of Saudi Arabia,

*King Abdullah University of Science and Technology, Functional Materials Design, Discovery and Development Research Group, Advanced Membranes and Porous Materials Center, Thuwal 23955-6900, Kingdom of Saudi Arabia,

『King Abdullah University of Science and Technology, Photonics Laboratory, Computer, Electrical and Mathematical Sciences and Engineering Division, Thuwal 23955-6900, Kingdom of Saudi Arabia,

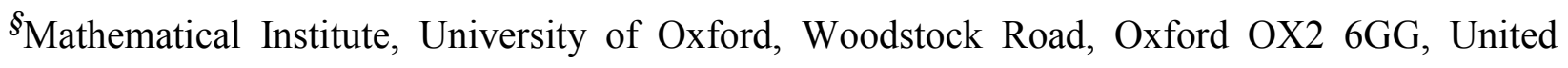
Kingdom

\section{AUTHOR INFORMATION}

Corresponding Author

*Email: omar.abdelsaboor@kaust.edu.sa 
ABSTRACT: Hybrid organic-inorganic perovskite crystals have recently become one of the most important classes of photoactive materials in the solar cell and optoelectronic communities. Albeit improvements focused on state-of-the-art technology including various fabrication methods, device architectures and surface passivation, progress is yet to be made in understanding the actual operational temperature on the electronic properties and the device performances. The substantial effect of temperature on the optoelectronic properties, charge separation, charge recombination dynamics and photoconversion efficiency (PCE) are explored. The results clearly demonstrated a significant enhancement in the carrier mobility, photocurrent, charge carrier lifetime and solar cell performance in the $60 \pm 5{ }^{\circ} \mathrm{C}$ temperature range. In this temperature range, perovskite crystal exhibits a highly symmetrical relaxed cubic structure with well-aligned domains that are perpendicular to a principal axis, thereby remarkably improving the device operation. This finding provides a new key variable component and paves the way towards using perovskite crystals in highly efficient photovoltaic cells.

\section{TOC GRAPHICS}

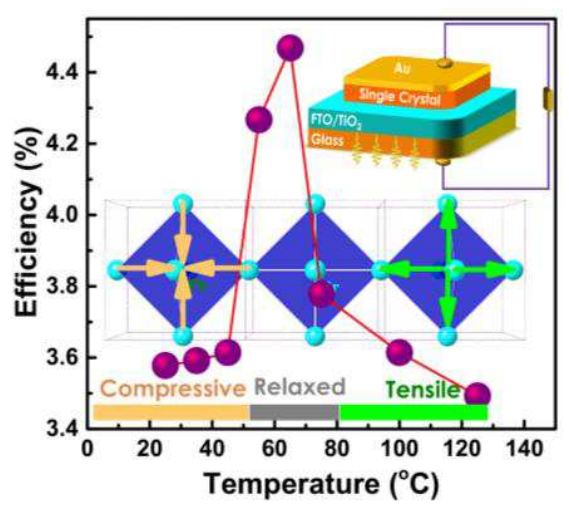


Hybrid organic-inorganic perovskites with outstanding performance have attracted substantial interest and emerged as one of the most promising materials for various applications, including photovoltaics, ${ }^{1,2}$ lasing $^{3}$ and photodetectors, ${ }^{4}$ because of their unprecedented long carrier dynamics, diffusion length, low exciton-binding energy, high absorption cross section and low trap density. ${ }^{5,6}$ It has been documented that these outstanding properties originate from the nature of the perovskite lattice structure. ${ }^{7}$ Although great progress has been made to achieve high photoconversion efficiencies (PCEs) from perovskite-based solar cells, severe instabilities frequently occur during device fabrication and operation, particularly in ambient conditions. ${ }^{8,9}$ For example, photo-induced decomposition in the presence of water, surface restructuring, lattice deformation, surface trap states and charge carrier-recombination centers at the grain boundaries are some of the most challenging issues affecting the use of perovskites polycrystalline films for device fabrication. ${ }^{10,11}$ Being in this regime, great efforts have been directed to passivate and enlarge the grain boundaries thereby reduce the trap density and non-radiative recombination centers resulting in high carrier mobilities and improved PCEs. ${ }^{12}$ The recently discovered perovskite single crystal, which has no grain boundaries, low trap densities, exceptional chargecarrier diffusion lengths, long charge carrier lifetime and high mobilities, could be an excellent alternative for polycrystalline counterparts.

Millimeter-scale single crystals of $\mathrm{MAPbX}_{3}\left(\mathrm{MA}=\mathrm{CH}_{3} \mathrm{NH}_{3}^{+} ; \mathrm{X}^{-} \mathrm{Br}^{-}, \mathrm{Cl}^{-}\right.$, and $\left.\mathrm{I}^{-}\right)$have been successfully grown even within minutes. ${ }^{5}$ However, growing these crystals to a desirable thickness is the greatest challenge impeding the development of perovskite single crystal-based solar cells. This serious problem inspired us to design and develop a novel approach called cavitation-triggered asymmetrical crystallization (CTAC), ${ }^{1}$ which was successfully used to 
fabricate a few-micron-thick monocrystalline $\mathrm{MAPbBr}_{3}$ film, demonstrating the first hole transporter free solar cell device with PCE of $\sim 6.5 \%$.

Recent experimental results revealed that the performance of CTAC-based single crystals depends substantially on both short-ultrasonic-pulse introduction and post-annealing treatments. ${ }^{1}$ Notably, the organic-inorganic hybrid crystal system belongs to the soft-matter category; therefore, it exhibits potential fluctuations, which can be stimulated by the external operational temperatures and pressures, even on the minute scale. ${ }^{13-15}$ In other words, it implicatively insinuates that the crystal lattice can strain, relax or compress as the annealing temperature varies, which may induce structural distortions in the perovskite lattice. Such strain-induced structural distortions generally in oxide perovskites are overwhelming with significant bandgap tunability. ${ }^{16}$ Here, we systematically explore the effect of temperature on the structural relaxation of a single crystal and the performance of hole transporter-free solar cells. We found that the optimal annealing temperature is $60 \pm 5{ }^{\circ} \mathrm{C}$, which drives the single crystal to a highly symmetrical relaxed cubic structure with well-aligned domains that are perpendicular to a principal axis, thereby significantly enhancing the carrier mobility, photocurrent, charge carrier lifetime and solar cell performance. In the current study, all the measurements were carried out with variable in situ temperatures and for those studies termed as annealing temperatures refer to annealing in a vacuum furnace with $5{ }^{\circ} \mathrm{C} / \mathrm{min}$ ramping rate for one hour and allowed to cool naturally under vacuum.

Freestanding single crystals (Figure S1, Supporting Information) and monocrystalline thin films (Figure S2) of various dimensions were obtained using the CTAC method (Figure 1b). X-ray diffraction measurements on the finely ground $\mathrm{MAPbBr}_{3}$ single-crystal powder under vacuum at variable in situ temperatures confirmed the cubic Pm $\overline{3 m}$ space group. As can be seen 
in Figure 1a, the thermal stability and crystallinity were preserved by retaining the cubic phase at 25-100 ${ }^{\circ} \mathrm{C}$, however at $125{ }^{\circ} \mathrm{C}$ showed additional Bragg reflections of $\mathrm{PbBr}_{2}$, suggesting the high-temperature degradation of $\mathrm{MAPbBr}_{3}$. Thermal stability in the temperature range $25-100{ }^{\circ} \mathrm{C}$ was expected because the MA cation can freely oscillate on a very short time scale $(\sim 0.2$ to $\sim 0.4$ ps) in the unit cell because of the low activation energy barrier and consequently, the small entropy change associated with the disordering of MA polar units. ${ }^{17}$ Note that the low temperatures $(<$ room temperature $(\mathrm{RT}))$ at which the rotational motion of $\mathrm{PbX}_{6}$ octahedra is coupled with the ordering of organic cations can induce phase transitions. ${ }^{18}$ Additionally, the possible ferroelectric domains resulting from the organic cations can increase the dielectric constants, ${ }^{19}$ directly affecting the charge transport characteristics and device performance; this issue will be discussed in the later sections.
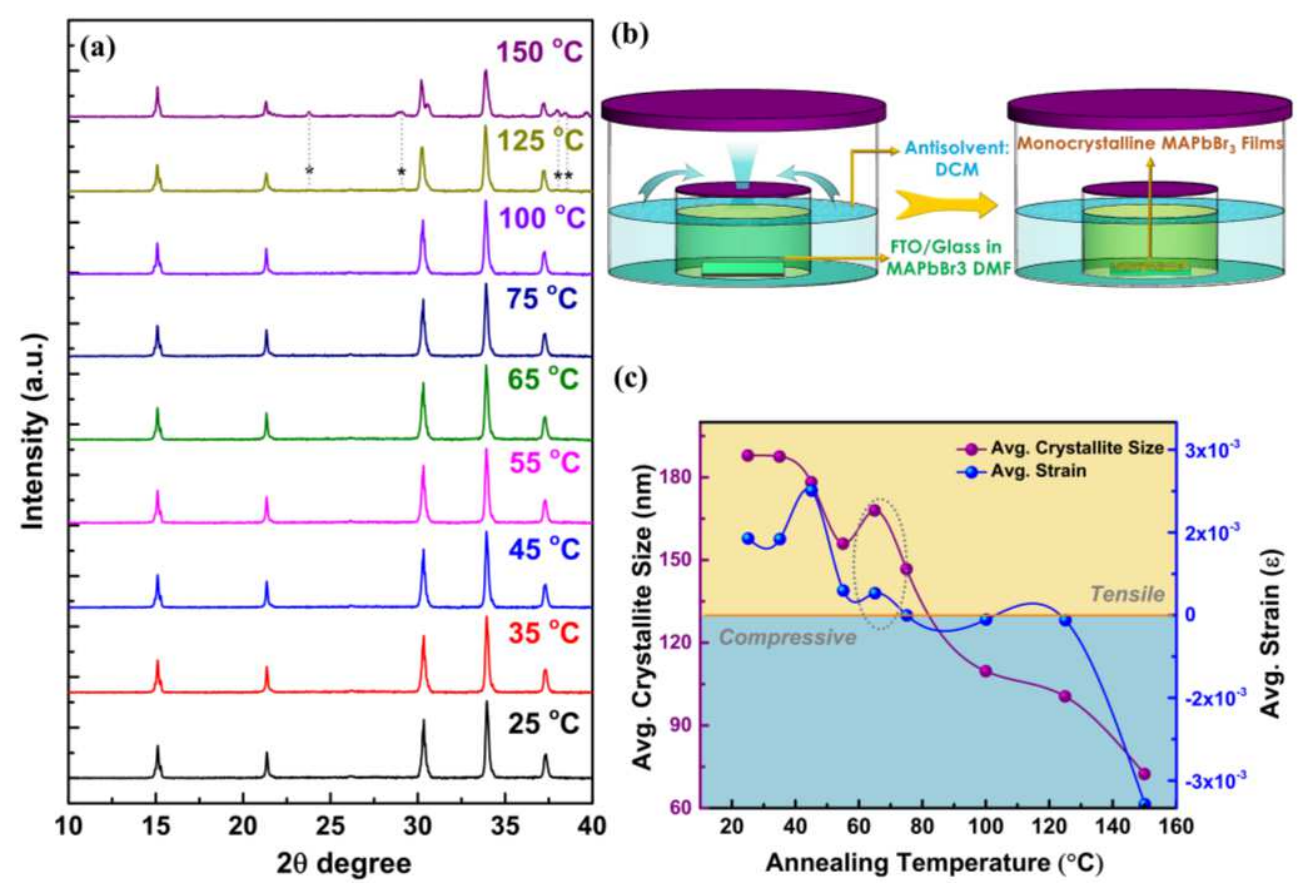

Figure 1. a) Variable-temperature vacuum powder XRD (PXRD) pattern of $\mathrm{MAPbBr}_{3}$. At $\geq 125$ ${ }^{\circ} \mathrm{C},{ }^{*}$ reflections indicate $\mathrm{PbBr}_{2}$. b) Schematic of the antisolvent route to grow a monocrystalline thin film via CTAC. c) Variation of the average crystallite size and strain as a function of temperature. 
While the crystal structure is thermally stable, thermal energies can incite the biaxial strain within the crystal lattice. The average strain, which was calculated using a Williamson hall plot, exhibits an interesting trend with temperature. The compressive strain was dominant at 25 ${ }^{\circ} \mathrm{C}$ and a sudden reversal to tensile strain was observed at $75{ }^{\circ} \mathrm{C}$. The minimal or relaxed strain was observed at temperatures range of $55-65{ }^{\circ} \mathrm{C}$ (Figure 1c). The variation of the lattice parameter with temperature (Figure S3) along various crystallographic orientations in a cubic system further confirms that the strain was incorporated in the crystal lattice. Therefore, based on these observations, we postulate that $60 \pm 5{ }^{\circ} \mathrm{C}$ corresponds to the relaxed cubic structure of $\mathrm{MAPbBr}_{3}$ and expect enhanced optoelectronic properties with enhanced device performance.

It is reasonable to investigate whether any morphological change is associated with the strained crystals because nano/superstructures may form with the release of this strain. ${ }^{20}$ To exclude the hydrated/polycrystalline surface $\operatorname{artifacts}^{20-22}$ in the current study, a euhedral crystal facet along the axis was selected for focused ion beam (FIB) scanning electron microscopy (SEM) investigations. Figure S4 (a-f), shows the SEM micrographs of the annealed $\mathrm{MAPbBr}_{3}$ single crystal. The annealing temperature studies were performed at $25,35,60,75$ and $125{ }^{\circ} \mathrm{C}$ for $1 \mathrm{~h}$ each using a vacuum convection oven. We examined the cross-section using a FIB at the edge of the crystal at $25^{\circ} \mathrm{C}$ (Figure S4a-b). For an annealing temperature of $35^{\circ} \mathrm{C}$, (Figure S4c) separated grains began to emerge because the crystal volume expanded, which frequently occurs during annealing. At $60{ }^{\circ} \mathrm{C}$, the number of grains increased, but interestingly, they formed wellaligned dense clusters of interconnected grains perpendicular to one of the crystal axes (Figure S4d). However, at higher annealing temperatures, such as 75 and $125^{\circ} \mathrm{C}$ (Figures S4e and S4f, respectively), these grain clusters disconnected, and individual flakes began to form. Based on our assumption, these flakes should originate from a $\mathrm{Pb}$-rich feature or grain. In other words, the 
grains and flakes on the surface formed because of the depletion of C-H-N elements and the formation of Pb-rich films. ${ }^{23}$ However the overall chemical composition showed slight variation as the temperature increases until $100{ }^{\circ} \mathrm{C}$, which reflects the chemical stability of $\mathrm{MAPbBr}_{3}$ (Figure S5). The correlation of the composition with device performance is discussed in later sections.

Although a minimal change was observed in the absorption optical bands, the HOMO levels showed an exciting trend, increasing by $0.13 \mathrm{eV}\left(\sim 3 \%\right.$ reduction) at $65{ }^{\circ} \mathrm{C}$ compared with $-5.75 \mathrm{eV}$ at $25{ }^{\circ} \mathrm{C}$ and gradually decreasing to $-5.70 \mathrm{eV}$ above $100{ }^{\circ} \mathrm{C}$. These results reveal an operational window in which the device output can be harvested in its full capacity (Figure S6S8, See Supporting Information). To gain additional insight into the electrical properties of the strained/relaxed crystal, Hall measurements were carried out under dark conditions. While Hall coefficient and carrier mobility (Figure S9a) were higher, the carrier density and resistivity (Figure S9b) were lower at $65{ }^{\circ} \mathrm{C}$ in good agreement with the device performance (discussed later). Lower carrier concentration $(n)$ and higher hall mobility $(\mu)$ are expected following the relations: $n=1 / R_{H} \cdot q$ and $\mu=R_{H} \cdot \sigma$, where conductivity $\sigma=1 / \rho$ and $q$ is the electron charge. Two dominant phenomena likely control these mobilities. ${ }^{24}$ In a disordered semiconductor, temperature activation processes come into play upon annealing, ${ }^{25}$ and it is reasonable to expect the mobility to increase with temperature up to a certain temperature (65 ${ }^{\circ} \mathrm{C}$ ). At high temperatures (above $65^{\circ} \mathrm{C}$ ), the screening processes dominate, and hence, the mobility decreases. ${ }^{26,27}$ Theoretically, higher electron transmission occurs because of the delocalized electronic states in a high-symmetry crystal, which further corroborates the temperature-dependent conductivity and mobility indicated by the XRD results. ${ }^{28}$ 

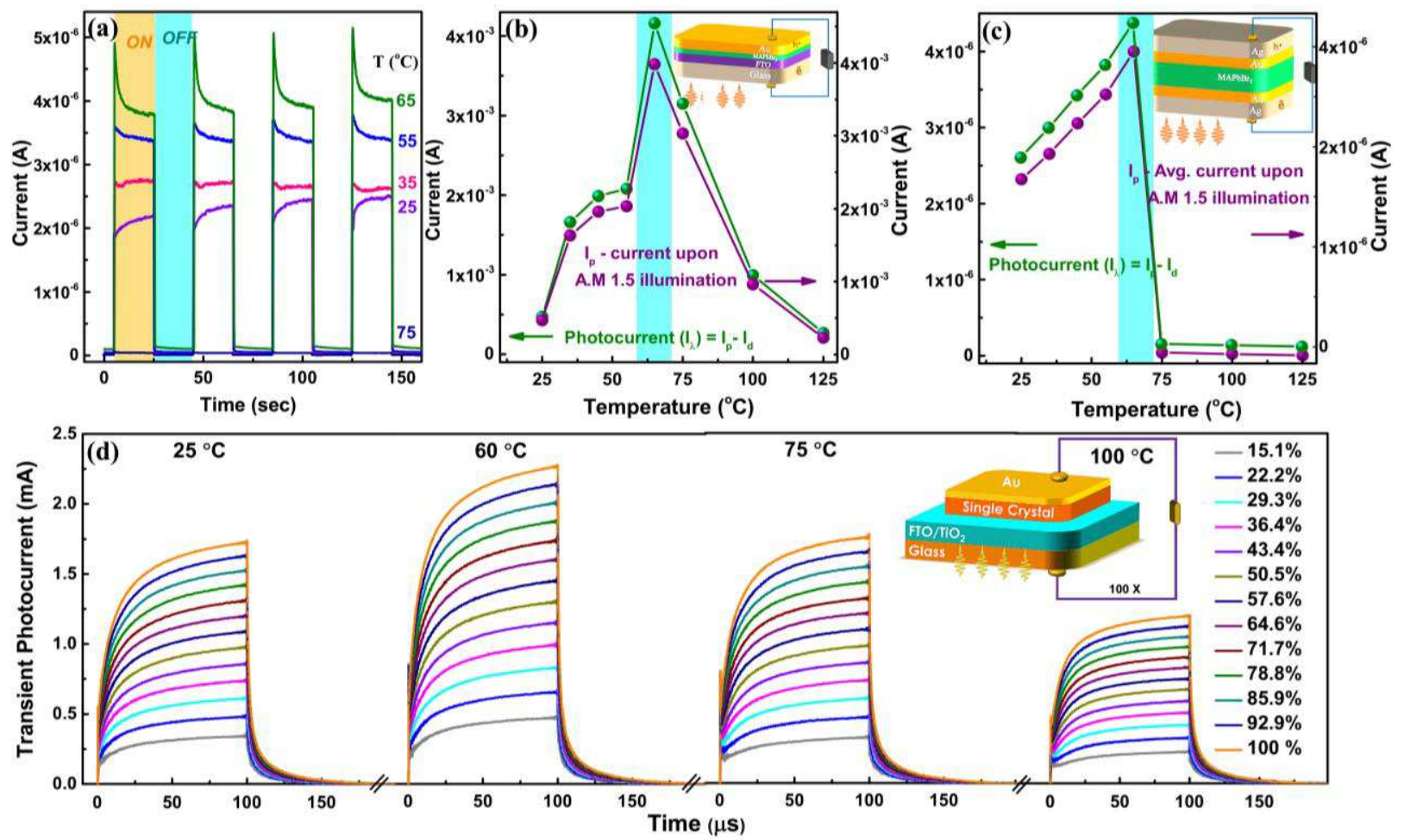

Figure 2. a) Steady-state on and off photodetector responsive cycles under A.M 1.5 G 1-Sun illumination. Variation of the current upon illumination and average photocurrent as a function of temperature for the b) thicker freestanding $\mathrm{MAPbBr}_{3}$ single crystal and c) microcrystalline thin film. d) Illumination-dependent transient photocurrent traces on perovskite single-crystalline thin film at various temperatures as indicated in the figure.

Taking into account the structural, morphological optical, electrical and electronic band alignment analyses, it is therefore, fairly established that the single-crystal device operates with maximum performance at $60 \pm 5{ }^{\circ} \mathrm{C}$. To quickly verify this hypothesis, two steady-state photodetectors (PD) with $\mathrm{Au} / \mathrm{MAPbBr}_{3} / \mathrm{Au}$ (Figure 2b) as free-standing crystal $\mathrm{PD}$ and $\mathrm{FTO} / \mathrm{MAPbBr}_{3} / \mathrm{Au}$ (Figure 2c) as a monocrystalline thin film $\mathrm{PD}$ and were investigated to ascertain the behaviors of thicker ( $\mathrm{mm}$ scale) and thinner $(\mu \mathrm{m})$ crystals. The detector was illuminated with A.M $1.5 \mathrm{G}$ solar light $\left(100 \mathrm{~mW} \mathrm{~cm}^{-2}\right)$ in an ambient atmosphere $(\geq 55 \%$ relative humidity) for both freestanding crystals and the Fluorine-doped tin oxide (FTO) substrate. The average current under illumination and the photocurrent $\left(I_{\lambda}=I_{p}-I_{d}\right.$ where $I_{p}$ and $I_{d}$ are the 
currents under illumination and in the dark, respectively) showed increasing trends up to $65{ }^{\circ} \mathrm{C}$. It should be noted that the magnitude of the photocurrent enhancement showed slight variation in the observed trend which depend on the detector geometry and alignment of the band levels. ${ }^{29-31}$ A sudden decrease in the photocurrent was observed in both the thicker and thinner single crystals from $75^{\circ} \mathrm{C}$ to $125^{\circ} \mathrm{C}$. In addition, a few on-and-off cycles (Figure 2a) were performed to test the detector's temporal stability response. Interestingly, a similar trend was recurrent as discerned with the carrier mobilities, further fortifying the hypothesis.

To shed light on the charge-transport mechanisms in the solar cell devices (discussed later), we have collected photo-transient measurements using a square-pulse white light-emitting diode (LED) with turn-on and turn-off speeds below 50 ns. Careful examination of transient photocurrent data, rise upon reaching steady state is dependent on the illumination intensity and reveal that the transport is trap assisted (Figure $2 \mathrm{~d})$. The initial faster rise and decay ( $\sim 36 \mu$ s and $\sim 35 \mu$ s, respectively) with an increasingly long persistent transient tail with temperature infer to dynamic processes involved in trapping/detrapping of carriers in the thermally active trap states. $^{32}$ Both steady state and transient behaviors confirm that the maximum photo-generated output current occurred at $60 \pm 5{ }^{\circ} \mathrm{C}$. This result further supports the existence of strain because deep traps can originate from changes in the bond distances ${ }^{33}$ resulting from the variation in the lattice parameter with temperature.

To understand the bulk optical properties of the single crystals, time-resolved photoluminescence (PL) experiments of $\mathrm{CH}_{3} \mathrm{NH}_{3} \mathrm{Br}_{3}$ single crystals were performed by timecorrelated single photon counting (TCSPC) upon two-photon excitation (2p). ${ }^{21}$ The samples were optically excited at $800 \mathrm{~nm}$ with a pump fluence of $240 \mathrm{~nJ} / \mathrm{cm}^{2}$, and the PL was monitored at 570 nm (Figure 3a-c, Figure S10a, b). Notably, no apparent change in peak position was observed in 
the studied temperature range. The experimental data were fitted to a model described elsewhere (Figure S9, See Supporting Information). ${ }^{34}$ In other words, the recombination lifetimes obtained from the PL decays increased as the temperature changed from $25^{\circ} \mathrm{C}$ to $55^{\circ} \mathrm{C}$, leading to an increase in the photo-generated charge carrier density. ${ }^{4}$
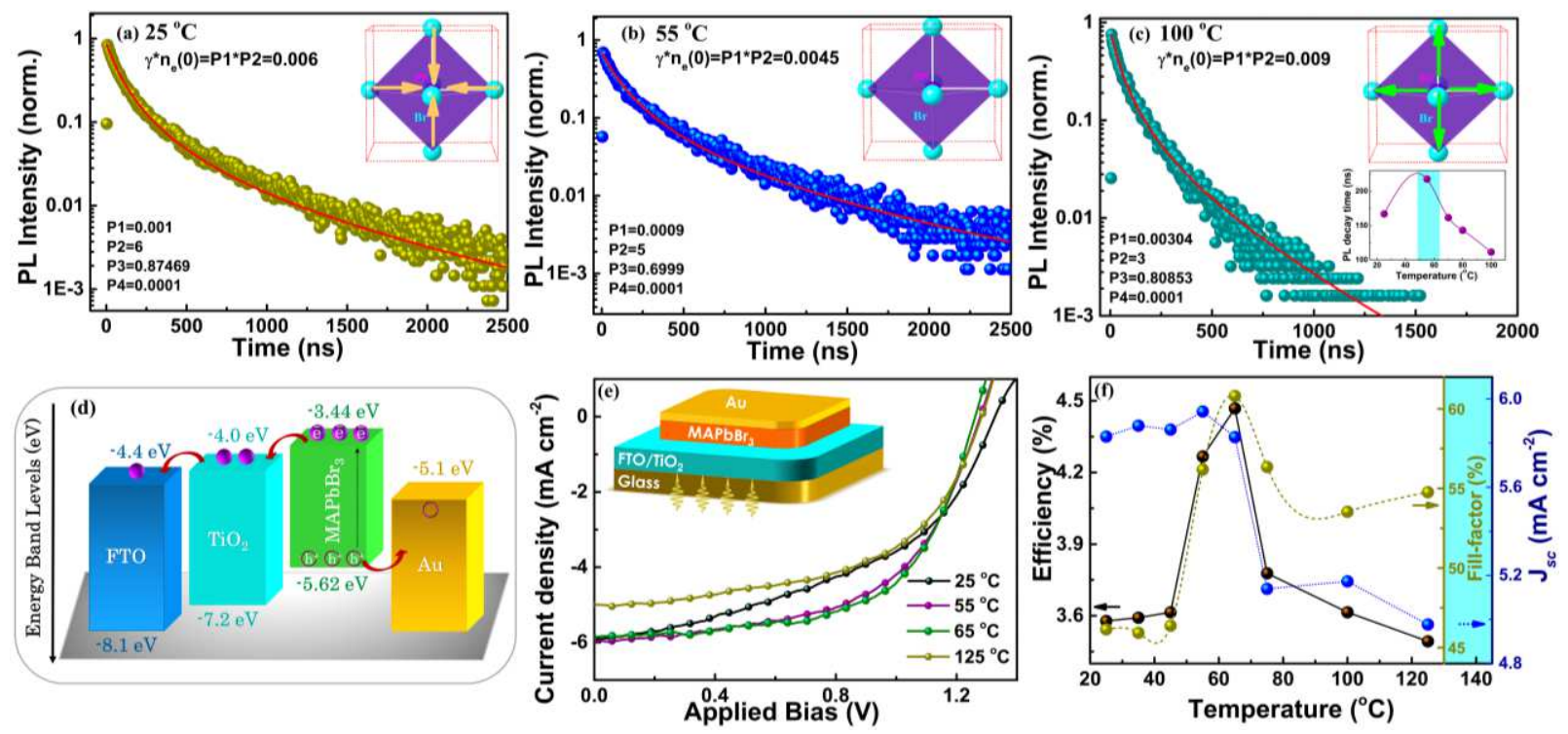

Figure 3. (a-c) PL intensity decay at different temperatures after $2 p$ excitation. Symbols are experimental data, lines are theoretical curves described by Eqn. S2 (supporting Information) with parameters shown in corresponding panel. Temperature dependence of the decay time (relative units) is shown in the inset of figure 5c. The insets show simplified unit cells without MA units to elucidate the strain, which is marked with arrows. d) Schematic of the band alignment energy level. (e, f) Current-voltage characteristics and variation of the obtained device parameters as a function of temperature.

Finally, to examine the performance-optical-structural-electronic (POSE) property correlations with the effects of annealing on the device efficiency, standard solar cell architecture was built with a monocrystalline thin film using the CTAC method. The reduced barrier between the perovskite $\mathrm{HOMO}$ at $65{ }^{\circ} \mathrm{C}$ and the $\mathrm{Au}$ electrode can facilitate efficient hole collection (Figure 3d). The current density-voltage characteristics are presented in Figure 3e. The highest PCE for the $\sim 4-\mu$ m-thick $\mathrm{MAPbBr}_{3}$ thin film was $\sim 6.5 \%$, whereas the highest reproducible 
thickness $(\sim 7-10 \mu \mathrm{m})$ exhibited a value of $\sim 3.5 \%$. The current study aimed to study the POSE relationship in a single-crystal based device by revealing the exact mechanisms and thereby resolving the issues and determining the operational window for future possible high-efficiency modules. Regarding the main hysteresis issue, ${ }^{35}$ the $\mathrm{MAPbBr}_{3}$ single crystal device also showed considerable detrimental effects. However, when $\mathrm{TiO}_{2}$ was used as the electron transport layer (ETL), the hysteresis was suppressed, resulting in a higher Voc of $1.4 \mathrm{eV}^{1}$; a detailed explanation of hysteresis is beyond the scope of the current work. The PCE increased by $\sim 25 \%$ at $65{ }^{\circ} \mathrm{C}$ and gradually decreased by $1.02 \%$ at $100{ }^{\circ} \mathrm{C}$ compared with the actual efficiency of $3.578 \%$ at $25{ }^{\circ} \mathrm{C}$ (Figure 3f). A similar trend was observed in the fill factor, which increased by $\sim 32 \%$ at $65{ }^{\circ} \mathrm{C}$ compared with that at $25^{\circ} \mathrm{C}$. Therefore, the correlation of the device performance from the XRD analyses, showed the cubic system was in its relaxed form, supported the device statistics. In addition, the highest performance for the reported $\mathrm{MAPbBr}_{3}$ monocrystalline film solar cells was found at temperature of $60{ }^{\circ} \mathrm{C}$ and is correlated with the SEM morphology. Similar to the case of annealed $\mathrm{MAPbI}_{3}$ thin films solar cells, ${ }^{36}$ we suggest that conversion of the precursors (MABr and $\left.\mathrm{PbBr}_{2}\right)$ to the perovskite $\left(\mathrm{MAPbBr}_{3}\right)$ materialized completely with additional aid from annealing within a temperature range of $60^{\circ} \mathrm{C}$. By contrast, separate, distinct flakes form when the annealing temperature exceeds $60{ }^{\circ} \mathrm{C}$. Besides the bulk properties of perovskite such as strain and optoelectronic properties, there could be several other factors that can affect the performance, such as interface recombination, charge separation ability of the contacts, and the integrity of cell structure that drives for enhanced performance at $60 \pm 5{ }^{\circ} \mathrm{C}$.

Impedance spectroscopy (IS) was employed to extract the key components of the circuits and thereby understand the carrier diffusion and recombination processes (Figure S11). Representative Nyquist plots at all temperatures showed two distinct semicircles, which were 
fitted to the equivalent circuit (Figure S11a) similar to those reported elsewhere for perovskite solar cells. ${ }^{36}$ The high-frequency semi-circle is magnified to show the better fit for obtaining the resistances (Figure S11b). The resistances in the two semicircles in the higher frequency and lower frequency regimes are attributed to the charge transfer/ recombination resistance $\left(R_{\text {rec }}\right)$ and the charge/ mass transport resistance at the interface $\left(R_{\text {trans }}\right)$ respectively. ${ }^{37}$ Contact resistances arising from the transport layers and apparatus are represented in series resistance $\left(R_{s}\right)$. The distortion of the semicircle in the high-frequency regimes can arise from the electrical connectors. The total capacitance was estimated from the constant phase shift elements (CPE) as shown in the simple equivalent circuit. The low-frequency $p$ values for CPE at low temperatures were considered between 0.7 to 1 however decreased at higher temperatures, where in-depth understanding by shedding light on the low-frequency effects are still under debate due to the double layer capacitance/ion migration and is out of the scope of the current work. ${ }^{38,39}$ However, following in the systems with two varied charges, the case at higher temperature yielding a single semicircle at high frequency can be asserted to the absence of ion diffusion. ${ }^{36}$ The $\mathrm{R}_{\text {rec }}$ was found to be $165 \mathrm{M} \Omega$ at $65^{\circ} \mathrm{C}$ that dropped to $\sim 80 \mathrm{M} \Omega$ at $75{ }^{\circ} \mathrm{C}$ and $\sim 50 \mathrm{M} \Omega$ at $125 \mathrm{C}^{\circ}$, respectively. Similarly, the $R_{\text {trans }}$ resistance decreased to $\sim 10 \mathrm{M} \Omega$ at $60{ }^{\circ} \mathrm{C}$ from $\sim 49 \mathrm{M} \Omega$ at RT and $\sim 28 \mathrm{M} \Omega$ at $125^{\circ} \mathrm{C}$, respectively (Figure S11 (c, d)). The effective electron lifetime, $\tau_{\mathrm{n}},\left(\tau_{\mathrm{n}}=R_{\mathrm{rec}} \times C_{\mu}\right)$ which indicates the charge recombination rate in the devices is longer for devices at $60{ }^{\circ} \mathrm{C}$ and shorter at $125^{\circ} \mathrm{C}$. The evolution of electron lifetime of the device with temperature is in good agreement with the PCE and the $V_{\text {oc }}$ of the solar cells. The central solar parameter diffusion length $\left(L_{d}\right)$ is calculated from the length of the single crystal $(L) \operatorname{using}^{40} L_{d}=\left(R_{r e c} / R_{t r}\right)^{1 / 2} L$ which is also longer at $65 \mathrm{C}^{\circ}$ compared to that at $125{ }^{\circ} \mathrm{C}$. In general, higher $R_{r e c}$ exhibit lower recombination rates and $R_{r e c}>R_{t r}, L_{d}>L$ indicates excellent carrier collection capability and vice versa. From 
the above observations, $\mathrm{MAPbBr}_{3}$ crystals in the present case allow efficient carrier collection with larger recombination resistance, higher lifetimes and longer diffusion lengths.

Hence, we limited our analysis based on the charge recombination resistances and recombination kinetics. The decreased efficiency at temperatures $\left(>100{ }^{\circ} \mathrm{C}\right)$ is generally considered a default issue in most solar technologies. ${ }^{41}$ However, the diffusion of the top electrode $\mathrm{Au}$ ) into the perovskite single-crystal device can worsen this effect. Importantly, to balance the HOMO level, electrical resistance, modest carrier mobility and improved lifetimes, in connection with the annealing temperatures, defining a conservative operating window for $\mathrm{MAPbBr}_{3}$ single-crystal devices of $60 \pm 5{ }^{\circ} \mathrm{C}$ is optimal.

In summary, we report the first direct correlation of the annealing temperature with the structural, optical, charge carrier dynamics, electrical and electronic properties, and device performance of perovskite single crystal solar cells. Our experimental results conclusively demonstrate that the optimal annealing temperature is $60 \pm 5^{\circ} \mathrm{C}$ for $\mathrm{MAPbBr}_{3}$ because at this temperature, the single crystal assumes a highly symmetrical relaxed cubic crystal structure with well-aligned domains that are perpendicular to a principal axis. Additionally, the lower transport resistance coupled with higher recombination resistance, high carrier mobilities substantiate the claim for enhanced performance at $60 \pm 5{ }^{\circ} \mathrm{C}$ thus unlocking a key puzzle of device operational Goldilocks. These findings will potentially help the field to understanding the nature and effect of the actual-operational temperature on solar cell device performance and provide a new key element to further optimize the performance of solar cells based on this promising class of photoactive materials. 


\section{Acknowledgments}

King Abdullah University of Science and Technology (KAUST) supported the reported work.

\section{Competing Financial Interests}

The authors declare no competing financial interests.

\section{Supporting Information}

Supporting Information contains experimental details of $\mathrm{MAPbBr}_{3}$ monocrystalline films synthesis, device fabrication and characterization, X-ray diffraction Strain Calculations, SEM images of the single crystals and monocrystalline thin films, crystal lattice parameters with respect to each Bragg reflection, compositional analysis, absorption spectra, Photoelectron spectroscopy in air (PESA) measurements, temperature dependent energy level diagram, temperature dependent Time-resolved PL measurements, transient photocurrent and impedance spectroscopy measurements of $\mathrm{MAPbBr}_{3}$ single crystal. 


\section{References}

(1) Peng, W.; Wang, L. F.; Murali, B.; Ho, K. T.; Bera, A.; Cho, N.; Kang, C. F.; Burlakov, V. M.; Pan, J.; Sinatra, L.; et al. Solution-Grown Monocrystalline Hybrid Perovskite Films for Hole-Transporter-Free Solar Cells. Adv. Mater. 2016, 28, 3383-3390.

(2) Green, M. A.; Emery, K.; Hishikawa, Y.; Warta, W.; Dunlop, E. D. Solar Cell Efficiency Tables (version 48). Prog. Photovoltaics 2016, 24, 905-913.

(3) Pan, J.; Sarmah, S. P.; Murali, B.; Dursun, I.; Peng, W.; Parida, M. R.; Liu, J.; Sinatra, L.; Alyami, N.; Zhao, C.; et al. Air-Stable Surface-Passivated Perovskite Quantum Dots for Ultra-Robust, Single- and Two-Photon-Induced Amplified Spontaneous Emission. J. Phys. Chem. Lett. 2015, 6, 5027-5033.

(4) Murali, B.; Saidaminov, M. I.; Abdelhady, A. L.; Peng, W.; Liu, J.; Pan, J.; Bakr, O. M.; Mohammed, O. F. Robust and Air-Stable Sandwiched Organo-Lead Halide Perovskites for Photodetector Applications. J. Mater. Chem. C 2016, 4, 2545-2552.

(5) Saidaminov, M. I.; Abdelhady, A. L.; Murali, B.; Alarousu, E.; Burlakov, V. M.; Peng, W.; Dursun, I.; Wang, L.; He, Y.; Maculan, G.; et al. High-Quality Bulk Hybrid Perovskite Single Crystals within Minutes by Inverse Temperature Crystallization. Nat. Commun. 2015, 6, 7586.

(6) Zhumekenov, A. A.; Saidaminov, M. I.; Haque, M. A.; Alarousu, E.; Sarmah, S. P.; Murali, B.; Dursun, I.; Miao, X.-H.; Abdelhady, A. L.; Wu, T.; et al. Formamidinium Lead Halide Perovskite Crystals with Unprecedented Long Carrier Dynamics and Diffusion Length. ACS Energy Lett. 2016, 1, 32-37.

(7) Piatkowski, P.; Cohen, B.; Ponseca, C. S.; Salado, M.; Kazim, S.; Ahmad, S.; Sundström, V.; Douhal, A. Unraveling Charge Carriers Generation, Diffusion, and Recombination in Formamidinium Lead Triiodide Perovskite Polycrystalline Thin Film. J. Phys. Chem. Lett. 2016, 7, 204-210. 
(8) Yang, J.; Siempelkamp, B. D.; Liu, D.; Kelly, T. L. Investigation of $\mathrm{CH}_{3} \mathrm{NH}_{3} \mathrm{PbI}_{3}$ Degradation Rates and Mechanisms in Controlled Humidity Environments Using insitu Techniques. ACS Nano 2015, 9, 1955-1963.

(9) Tsai, H.; Nie, W.; Blancon, J.-C.; Stoumpos, C. C.; Asadpour, R.; Harutyunyan, B.; Neukirch, A. J.; Verduzco, R.; Crochet, J. J.; Tretiak, S.; et al. High-Efficiency TwoDimensional Ruddlesden-Popper Perovskite Solar Cells. Nature 2016, 536, 312-316.

(10) Xing, J.; Wang, Q.; Dong, Q.; Yuan, Y.; Fang, Y.; Huang, J. Ultrafast Ion Migration in Hybrid Perovskite Polycrystalline Thin Films under Light and Suppression in Single Crystals. Phys. Chem. Chem. Phys. 2016, 18, 30484-30490.

(11) Nie, W.; Blancon, J. C.; Neukirch, A. J.; Appavoo, K.; Tsai, H.; Chhowalla, M.; Alam, M. A.; Sfeir, M. Y.; Katan, C.; Even, J.; et al. Light-Activated Photocurrent Degradation and Self-Healing in Perovskite Solar Cells. Nat. Commun. 2016, 7, 11574.

(12) Xiao, Z.; Dong, Q.; Bi, C.; Shao, Y.; Yuan, Y.; Huang, J. Solvent Annealing of Perovskite-Induced Crystal Growth for Photovoltaic-Device Efficiency Enhancement. Adv. Mater. 2014, 26, 6503-6509.

(13) Conings, B.; Drijkoningen, J.; Gauquelin, N.; Babayigit, A.; D'Haen, J.; D'Olieslaeger, L.; Ethirajan, A.; Verbeeck, J.; Manca, J.; Mosconi, E.; et al. Intrinsic Thermal Instability of Methylammonium Lead Trihalide Perovskite. Adv. Energy Mater. 2015, 5, 1500477.

(14) Wang, L.; Wang, K.; Zou, B. Pressure-Induced Structural and Optical Properties of Organometal Halide Perovskite-Based Formamidinium Lead Bromide. J. Phys. Chem. Lett. 2016, 7, 2556-2562.

(15) Han, D.; Bang, J.; Xie, W.; Meunier, V.; Zhang, S. Phonon-Enabled Carrier Transport of Localized States at Non-Polar Semiconductor Surfaces: A First-Principles-Based Prediction. J. Phys. Chem. Lett. 2016, 7, 3548-3553.

(16) Berger, R. F.; Fennie, C. J.; Neaton, J. B. Band Gap and Edge Engineering via Ferroic Distortion and Anisotropic Strain: The Case of $\mathrm{SrTiO}_{3}$. Phys. Rev. Lett. 2011, 107, 146804. 
(17) Bakulin, A. A.; Selig, O.; Bakker, H. J.; Rezus, Y. L. A.; Müller, C.; Glaser, T.; Lovrincic, R.; Sun, Z.; Chen, Z.; Walsh, A.; et al. Real-Time Observation of Organic Cation Reorientation in Methylammonium Lead Iodide Perovskites. J. Phys. Chem. Lett. 2015, 6, 3663-3669.

(18) Stoumpos, C. C.; Malliakas, C. D.; Kanatzidis, M. G. Semiconducting Tin and Lead Iodide Perovskites with Organic Cations: Phase Transitions, High Mobilities, and NearInfrared Photoluminescent Properties. Inorg. Chem. 2013, 52, 9019-9038.

(19) Frost, J. M.; Butler, K. T.; Brivio, F.; Hendon, C. H.; van Schilfgaarde, M.; Walsh, A. Atomistic Origins of High-Performance in Hybrid Halide Perovskite Solar Cells. Nano Lett. 2014, 14, 2584-2590.

(20) Grote, C.; Berger, R. F. Strain Tuning of Tin-Halide and Lead-Halide Perovskites: A First-Principles Atomic and Electronic Structure Study. J. Phys. Chem. C 2015, 119, 22832-22837.

(21) Murali, B.; Dey, S.; Abdelhady, A. L.; Peng, W.; Alarousu, E.; Kirmani, A. R.; Cho, N.; Sarmah, S. P.; Parida, M. R.; Saidaminov, M. I.; et al. Surface Restructuring of Hybrid Perovskite Crystals. ACS Energy Lett. 2016, 1, 1119-1126.

(22) Fang, H.-H.; Adjokatse, S.; Wei, H.; Yang, J.; Blake, G. R.; Huang, J.; Even, J.; Loi, M. A. Ultrahigh Sensitivity of Methylammonium Lead Tribromide Perovskite Single Crystals to Environmental Gases. Sci. Adv. 2016, 2, e1600534.

(23) Guerrero, A.; You, J.; Aranda, C.; Kang, Y. S.; Garcia-Belmonte, G.; Zhou, H.; Bisquert, J.; Yang, Y. Interfacial Degradation of Planar Lead Halide Perovskite Solar Cells. ACS Nano 2016, 10, 218-224.

(24) Pisoni, A.; Jaćimović, J.; Barišić, O. S.; Spina, M.; Gaál, R.; Forró, L.; Horváth, E. UltraLow Thermal Conductivity in Organic-Inorganic Hybrid Perovskite $\mathrm{CH}_{3} \mathrm{NH}_{3} \mathrm{PbI}_{3} . J$. Phys. Chem. Lett. 2014, 5, 2488-2492.

(25) Vissenberg, M. C. J. M.; Matters, M. Theory of the Field-Effect Mobility in Amorphous Organic Transistors. Phys. Rev. B 1998, 57, 12964-12967. 
(26) Labram, J. G.; Fabini, D. H.; Perry, E. E.; Lehner, A. J.; Wang, H.; Glaudell, A. M.; Wu, G.; Evans, H.; Buck, D.; Cotta, R.; et al. Temperature-Dependent Polarization in FieldEffect Transport and Photovoltaic Measurements of Methylammonium Lead Iodide. $J$. Phys. Chem. Lett. 2015, 6, 3565-3571.

(27) Wehrenfennig, C.; Eperon, G. E.; Johnston, M. B.; Snaith, H. J.; Herz, L. M. High Charge Carrier Mobilities and Lifetimes in Organolead Trihalide Perovskites. Adv. Mater. 2014, 26, 1584-1589.

(28) Berdiyorov, G. R.; Madjet, M. E.; El-Mellouhi, F.; Peeters, F. M. Effect of Crystal Structure on the Electronic Transport Properties of the Organometallic Perovskite $\mathrm{CH}_{3} \mathrm{NH}_{3} \mathrm{PbI}_{3}$. Sol. Energy Mat. Sol. Cells 2016, 148, 60-66.

(29) Li, R.; Yang, J.; Huo, N.; Fan, C.; Lu, F.; Yan, T.; Wei, Z.; Li, J. Effect of Electrical Contact on the Performance of $\mathrm{Bi}_{2} \mathrm{~S}_{3}$ Single Nanowire Photodetectors. ChemPhysChem 2014, 15, 2510-2516.

(30) Murali, B.; Krupanidhi, S. B. Transport Properties of $\mathrm{CuIn}_{1-\mathrm{x}} \mathrm{Al}_{\mathrm{x}} \mathrm{Se}_{2} / \mathrm{AZnO}$ Heterostructure for Low Cost Thin Film Photovoltaics. Dalton Trans. 2014, 43, 19741983.

(31) Banavoth, M.; Dias, S.; Krupanidhi, S. B. Near-Infrared Photoactive $\mathrm{Cu}_{2} \mathrm{ZnSnS}_{4}$ Thin Films by Co-Sputtering. AIP $A d v$. 2013, 3, 082132.

(32) Li, Z.; Gao, F.; Greenham, N. C.; McNeill, C. R. Comparison of the Operation of Polymer/Fullerene, Polymer/Polymer, and Polymer/Nanocrystal Solar Cells: A Transient Photocurrent and Photovoltage Study. Adv. Funct. Mater. 2011, 21, 1419-1431.

(33) Buin, A.; Comin, R.; Xu, J.; Ip, A. H.; Sargent, E. H. Halide-Dependent Electronic Structure of Organolead Perovskite Materials. Chem. Mater. 2015, 27, 4405-4412.

(34) Zhang, W.; Pathak, S.; Sakai, N.; Stergiopoulos, T.; Nayak, P. K.; Noel, N. K.; Haghighirad, A. A.; Burlakov, V. M.; deQuilettes, D. W.; Sadhanala, A.; et al. Enhanced Optoelectronic Quality of Perovskite Thin Films with Hypophosphorous Acid for Planar Heterojunction Solar Cells. Nat. Commun. 2015, 6, 10030. 
(35) Unger, E. L.; Hoke, E. T.; Bailie, C. D.; Nguyen, W. H.; Bowring, A. R.; Heumuller, T.; Christoforo, M. G.; McGehee, M. D. Hysteresis and Transient Behavior in CurrentVoltage Measurements of Hybrid-Perovskite Absorber Solar Cells. Energy Environ. Sci. 2014, 7, 3690-3698.

(36) Bag, M.; Renna, L. A.; Adhikari, R. Y.; Karak, S.; Liu, F.; Lahti, P. M.; Russell, T. P.; Tuominen, M. T.; Venkataraman, D. Kinetics of Ion Transport in Perovskite Active Layers and Its Implications for Active Layer Stability. J. Am. Chem. Soc. 2015, 137, 13130-13137.

(37) Jamnik, J.; Maier, J. Treatment of the Impedance of Mixed Conductors Equivalent Circuit Model and Explicit Approximate Solutions. J. Electrochem. Soc. 1999, 146, 4183-4188.

(38) Bisquert, J. Theory of the Impedance of Electron Diffusion and Recombination in a Thin Layer. J. Phys. Chem. B 2002, 106, 325-333.

(39) Juarez-Perez, E. J.; Sanchez, R. S.; Badia, L.; Garcia-Belmonte, G.; Kang, Y. S.; MoraSero, I.; Bisquert, J. Photoinduced Giant Dielectric Constant in Lead Halide Perovskite Solar Cells. J. Phys. Chem. Lett. 2014, 5, 2390-2394.

(40) Gonzalez-Pedro, V.; Juarez-Perez, E. J.; Arsyad, W.-S.; Barea, E. M.; Fabregat-Santiago, F.; Mora-Sero, I.; Bisquert, J. General Working Principles of $\mathrm{CH}_{3} \mathrm{NH}_{3} \mathrm{PbX}_{3}$ Perovskite Solar Cells. Nano Lett. 2014, 14, 888-893.

(41) Skoplaki, E.; Palyvos, J. A. On the Temperature Dependence of Photovoltaic Module Electrical Performance: A Review of Efficiency/Power Correlations. Sol. Energy 2009, $83,614-624$. 